\title{
Clinical profile and outcome of HIV-TB Co-Infection at a centre of excellence for HIV care
}

\author{
Diwakar Tumkur Narasimhamurthy ${ }^{1}$, David Mathew Thomas², \\ Ravi Krishnegowda ${ }^{3}$, Asif Ali Thayyil ${ }^{4}$, Shruthi KR Nagar Mallesh ${ }^{5}$, Abdul Fahad ${ }^{6}$, \\ Raghavendra Byadigere Chikkahonappa ${ }^{7}$

\begin{abstract}
${ }^{1}$ Associate Professor, Department of Internal Medicine, Bangalore Medical College and Research Institute, ${ }^{2,4,7}$ PostGraduate Trainee, Department of Internal Medicine, Bangalore Medical College and Research Institute, ${ }^{3}$ Professor and Head, Department of Internal Medicine, Bangalore Medical College and Research Institute, ${ }^{5}$ Non-Clinical Research Fellow, Centre of Excellence for Anti-Retroviral Therapy Centre, Bowring and Lady Curzon Hospital, ${ }^{6}$ Final
\end{abstract} \\ Year Medical Student, Department of Internal Medicine, Bangalore Medical College and Research Institute
}

Background: Tuberculosis (TB) and Human Imuunodeficiency Virus (HIV) co-infection has detrimental effects on both the individual and the health care system especially in resource limited countries like India. Tuberculosis ranks among the most common cause of death in HIV patients. In this review we have analysed the clinical and immunological characteristics of HIV-TB coinfected patients and their clinical outcomes. Aims and Objectives: To assess the co-relation between socio-demographic characteristics, clinical and immunological Profile of HIV-TB co-infected patients and the clinical outcome. Materials and Methods: A retrospective clinical study of patient records at the Centre of Excellence for anti-retroviral therapy was done. The records of HIV-TB co-infected patients were collected and data extracted pertaining to the socio- demographic characteristics, clinical profiles and outcomes. Results: Among the 377 cases included as per criteria, $76.9 \%$ completed the treatment for TB while $23.1 \%$ patients died before treatment completion. Twenty-nine point seven percent of the patient population constituted women, while $0.5 \%$ was transgenders. Regarding the pattern of tuberculosis, $58.4 \%$ patients had extra pulmonary TB while $39.5 \%$ and $2.1 \%$ of the study population were diagnosed as pulmonary and disseminated TB respectively. Mean baseline CD4 count was 191 cells/mm3 and the mean CD4 count during first and second follow up were 298 and 362 cells $/ \mathrm{mm} 3$ respectively. There was a statistically significant correlation noted with poor clinical outcomes and low baseline CD4 counts. Conclusion: Age, gender, the clinical pattern of tuberculosis and the treatment category did not have a statistically significant association on the outcome. We found that the TB associated mortality in HIV co- infected patients had a direct correlation with the stage of HIV at presentation as there was a strongly significant association between low CD4 counts and adverse clinical outcomes.

Key words: HIV, Tuberculosis, Coinfection, CD-4 Counts
Access this article online Website:

http://nepjol.info/index.php/AJMS DOI: 10.3126/ajms.v9i2.17261 E-ISSN: 2091-0576 P-ISSN: 2467-9100

\section{INTRODUCTION}

Human Immunodeficiency Virus (HIV) and Tuberculosis (TB) co-infection is considered one of the most important public health problems in terms of the economic and social impact it has globally. Tuberculosis is the most common opportunistic infection associated with HIV. It is also the leading cause of morbidity and mortality in patients with HIV/AIDS in resource-limited settings. ${ }^{1}$

The immune suppression associated with HIV increases the risk of reactivation of latent tuberculosis and rapid

Address for correspondence:

Dr David Mathew Thomas, Post-Graduate Resident in Internal Medicine, Bangalore Medical College and Research Institute,

House No 1067, A Block, Sahakaranagara, Bangalore-560092, Tel: +91-8281793513

E-mail: davidmathew186@gmail.com 
progression to active TB infection. ${ }^{2} \mathrm{HIV}$ infects and destroys CD4+ $\mathrm{T}$ lymphocytes. CD4+ $\mathrm{T}$ lymphocytes are essential for effective cell mediated immune response to Mycobacterium tuberculosis. Activated T lymphocytes can induce the production of gamma interferon, which activates macrophages. These activated macrophages will limit the further active multiplication of TB bacilli. As the CD4+ function and count declines in HIV, there is a strong predisposition to tuberculosis. AIDS virus infection also interferes with the generation of effector memory CD4 T cell that migrate to the primary site of MTB infection - the lung - and dramatically increases risk of developing active TB. Tuberculosis is more difficult to diagnose and therefore progresses rapidly in HIV positive patients. ${ }^{3}$

The psycho-social challenges include stigma attached to the burden of double disease. Interaction between antitubercular and antiretroviral drugs has the potential for producing severe side effects and a long treatment duration of 18 to 24 months.

According to World Health Organization (WHO) report 2016, An estimated 1 million people living with HIV (PLHIV) worldwide fell ill with TB in 2016. TB is the leading cause of death among people with HIV, accounting for some 370,000 people who died from HIV-associated TB in 2016. Globally PLHIV are 21 times (16-27) more likely to fall ill with TB than those without HIV and 37\% of deaths among people with HIV due to TB. HIV infected patients are at high risk of mortality from multi-drug resistant and extensively drug-resistant TB. ${ }^{4}$

As per Government of India statistics (2015), India has an estimated 2.1 million people living with HIV (2015). ${ }^{5,6}$ In India, 55-60\% of AIDS patients reportedly have tuberculosis and it is one of the leading causes of death among people living with HIV/AIDS (PLHA). ${ }^{7}$ Collaborative Tuberculosis and HIV activities are essential to prevent, diagnose and treat $\mathrm{TB}$ among people with HIV and HIV among TB patients, for an optimal patient care.

\section{AIMS AND OBJECTIVE}

To assess the co-relation between socio-demographic characteristics, clinical and immunological Profile of HIVTB co-infected patients with that of the outcome.

\section{MATERIALS AND METHODS}

The records of HIV-TB co-infected patients maintained at the Centre for excellence for anti-retroviral therapy located at Bowring and Lady Curzon Hospital, Bangalore were collected and the data extracted pertaining to socio demographic characteristics, clinical profiles and outcomes. It is an observational cross-sectional clinical study

\section{Inclusion criteria}

Subjects living with HIV-1 infection who are followed longitudinally for their HIV health care in the ART Nodal Centre at Bowring and Lady Curzon Hospital, who have been diagnosed with tuberculosis.

We excluded patients with other causes of immune suppression like diabetes mellitus, chronic steroid abuse and immunosuppressive therapy as well as patients with insufficient follow up records

\section{Methodology}

The patient details were collected from the records maintained at the centre for excellence for anti-retroviral therapy at Bowring and Lady Curzon hospital.The sociodemographic, clinical and immunological profiles of the patients were compared with the outcomes.

The common trends among the selected profiles were assessed and the difference in outcomes was studied. The aim of the review was to analyse the inference and to know whether appropriate modifications in the line of treatment could be implemented.

\section{Statistical methods}

Descriptive and inferential statistical analysis was used in the present study. Significance was assessed at $5 \%$ level of significance. Chi-square/Fisher Exact test has been used to find the significance of study parameters on categorical scale between two or more groups,

\section{RESULTS}

A total of 377 patients were included in our study. Majority of patients (46.4\%) were in the age group of $31-40$ years of age with the mean age being $38.68 \pm 10.12$ years (Table-1). Our study showed that there was a strong male predominance comprising almost $70 \%$ of the HIV/TB co infection study population.

A total of $58.4 \%(n=220)$ of our patients were diagnosed to have Extra-Pulmonary tuberculosis (Table-2). Among the extra-pulmonary TB group, it was observed that lymph node tuberculosis was the commonest presentation in these co-infected patients.

Eighty two point five percent $(\mathrm{n}=311)$ of our patients were on category I ATT and $17.5 \%(\mathrm{n}=60)$ on category II ATT. The category of TB treatment did not have a significant impact on the clinical outcome of the study group as evidenced from the results. The mortality observed was $23.07 \%$ (Table-3). 
The single most common site of Tuberculosis affection was pulmonary $-39.5 \%(n=149)$ followed by TB lymphadenitis-23.3\% ( $\mathrm{n}=88)$ (Table-4).

CD-4 counts of the patients were analysed at various points in time of follow up as follows- Time-1-Baseline, Time-2-At end of 6 months and Time- 3 at 12 months (Table-5). The mean baseline CD-4 count in these patients were $191.76 \pm 171.37$ prior to initiating treatment. NR represents the patient group which did not have a serial CD-4 count recording in the subsequent visits.

In this study, we compared different parameters like age, the gender distribution, as to whether each had any statistically

\begin{tabular}{lcc}
\multicolumn{3}{l}{ Table 1: Age distribution of patients studied } \\
\hline Age in years & No. of patients & $\%$ \\
\hline $11-20$ & 10 & 2.7 \\
$21-30$ & 63 & 16.7 \\
$31-40$ & 175 & 46.4 \\
$41-50$ & 89 & 23.6 \\
$51-60$ & 29 & 7.7 \\
$61-70$ & 10 & 2.7 \\
$>70$ & 1 & 0.3 \\
Total & 377 & 100.0 \\
\hline
\end{tabular}

\begin{tabular}{|c|c|c|}
\hline Nature of TB & No. of patients & $\%$ \\
\hline Extra Pulmonary TB & 220 & 58.4 \\
\hline Pulmonary TB - sputum negative & 87 & 23.1 \\
\hline Pulmonary TB - sputum positive & 62 & 16.4 \\
\hline Disseminated TB & 8 & 2.1 \\
\hline Total & 377 & 100.0 \\
\hline
\end{tabular}

\begin{tabular}{|c|c|c|c|}
\hline \multirow[t]{2}{*}{ Location } & \multicolumn{2}{|c|}{ TB treatment outcome } & \multirow[t]{2}{*}{ Total (\%) } \\
\hline & Death $(\%)$ & $\begin{array}{c}\text { Treatment } \\
\text { completed (\%) }\end{array}$ & \\
\hline Cat I & $71(81.6)$ & $240(82.8)$ & $311(82.5)$ \\
\hline Cat II & $16(18.4)$ & $50(17.2)$ & $66(17.5)$ \\
\hline Total & 87 (100) & $290(100)$ & $377(100)$ \\
\hline
\end{tabular}

\begin{tabular}{lcc}
$\begin{array}{l}\text { Table 4: Pattern of TB in patients studied } \\
\text { Location }\end{array}$ & No. of patients & $\%$ \\
\hline Pulmonary & 149 & 39.5 \\
Lymph node & 88 & 23.3 \\
Abdominal Koch's & 67 & 17.8 \\
Pleural effusion & 33 & 8.8 \\
TB Meningitis & 27 & 7.2 \\
Miliary TB & 8 & 2.1 \\
Spinal TB & 3 & 0.8 \\
Pharyngeal & 1 & 0.3 \\
Genito-Urinary TB & 1 & 0.3 \\
Total & 377 & 100.0 \\
\hline
\end{tabular}

significant association with the end point outcome. The results were tabulated as depicted in the tables below.

Age, gender and the clinical pattern of Tuberculosis if taken as independent factors were not found to have a statistically significant impact on the outcome of these patients as shown in the following tables (Table-6, Table-7 and Table-8).

It was observed that patients affected with pleural effusion and Tuberculous meningitis had a statistically significant end-point of adverse outcomes in term of mortality compared with the other clinical TB types (Table-9).

A low baseline CD-4 counts in these patients was shown to have an adverse effect on the clinical outcomes as shown by the $p$ value above $(p<0.001)$. (Table-10) This led to the conclusion that $\mathrm{CD}-4$ counts at presentation

\begin{tabular}{|c|c|c|c|}
\hline CD4 & $\begin{array}{c}\text { No. of } \\
\text { patients }\end{array}$ & $\%$ & Mean $\pm S D$ \\
\hline \multicolumn{4}{|c|}{ Ist Analysis $(n=377)$} \\
\hline $1-50$ & 67 & 17.8 & $191.76 \pm 171.37$ \\
\hline $51-100$ & 74 & 19.6 & \\
\hline $101-200$ & 99 & 26.3 & \\
\hline $201-300$ & 56 & 14.9 & \\
\hline $301-500$ & 52 & 13.8 & \\
\hline$>500$ & 29 & 7.7 & \\
\hline \multicolumn{4}{|c|}{ IInd Analysis } \\
\hline $1-50$ & 8 & 2.1 & $298.00 \pm 188.69$ \\
\hline $51-100$ & 23 & 6.1 & \\
\hline $101-200$ & 58 & 15.4 & \\
\hline $201-300$ & 58 & 15.4 & \\
\hline $301-500$ & 74 & 19.6 & \\
\hline$>500$ & 35 & 9.3 & \\
\hline NR & 121 & 32.1 & \\
\hline \multicolumn{4}{|c|}{ IIIrd Analysis } \\
\hline $1-50$ & 6 & 1.6 & $362.85 \pm 196.53$ \\
\hline $51-100$ & 6 & 1.6 & \\
\hline $101-200$ & 20 & 5.3 & \\
\hline $201-300$ & 34 & 9.0 & \\
\hline $301-500$ & 68 & 18.0 & \\
\hline$>500$ & 33 & 8.8 & \\
\hline NR & 210 & 55.7 & \\
\hline
\end{tabular}

\begin{tabular}{|c|c|c|c|}
\hline \multirow{2}{*}{$\begin{array}{l}\text { Age in } \\
\text { years }\end{array}$} & \multicolumn{2}{|c|}{ TB treatment outcome } & \multirow[t]{2}{*}{ Total (\%) } \\
\hline & Death (\%) & $\begin{array}{c}\text { Treatment } \\
\text { completed (\%) }\end{array}$ & \\
\hline $11-20$ & $1(1.1)$ & $9(3.1)$ & $10(2.7)$ \\
\hline $21-30$ & $13(14.9)$ & $50(17.2)$ & $63(16.7)$ \\
\hline $31-40$ & $42(48.3)$ & $133(45.9)$ & $175(46.4)$ \\
\hline $41-50$ & $21(24.1)$ & $68(23.4)$ & 89 (23.6) \\
\hline $51-60$ & $6(6.9)$ & $23(7.9)$ & $29(7.7)$ \\
\hline $61-70$ & $3(3.4)$ & $7(2.4)$ & $10(2.7)$ \\
\hline$>70$ & $1(1.1)$ & $0(0)^{\prime}$ & $1(0.3)$ \\
\hline Total & 87 (100) & $290(100)$ & $377(100)$ \\
\hline
\end{tabular}


as well as those observed during follow up, showing an increment compared with the previous values were associated with a favorable outcome. Patients with a lower CD-4 count and a poor recovery of the same during each of the follow up times had a higher mortality as evidence from Figure-2.

\section{DISCUSSION}

Globally and in India, TB is one of the most common opportunistic infections affecting people with HIV. This assumes importance in a country like India which has 2.7 million HIV infections and $23 \%$ of the world's incident TB cases. HIV infection is often cited as an

\begin{tabular}{|c|c|c|c|}
\hline \multirow[t]{2}{*}{ Gender } & \multicolumn{2}{|c|}{ TB treatment outcome } & \multirow[t]{2}{*}{ Total (\%) } \\
\hline & Death (\%) & $\begin{array}{l}\text { Treatment } \\
\text { completed } \\
(\%)\end{array}$ & \\
\hline Female & $22(25.3)$ & $90(31)$ & $112(29.7)$ \\
\hline Male & $65(74.7)$ & $198(68.3)$ & $263(69.8)$ \\
\hline TG & $0(0)$ & $2(0.7)$ & $2(0.5)$ \\
\hline Total & $87(100)$ & $290(100)$ & $377(100)$ \\
\hline \multicolumn{4}{|c|}{$P=0.419$, Not significant, Chi-Square test } \\
\hline \multicolumn{4}{|c|}{$\begin{array}{l}\text { Table 8: PTB types of patients in relation to the } \\
\text { outcome }\end{array}$} \\
\hline \multirow{2}{*}{$\begin{array}{l}\text { If diagnosed } \\
\text { specify }\end{array}$} & \multicolumn{2}{|c|}{ TB treatment outcome } & Total (\%) \\
\hline & Death (\%) & $\begin{array}{c}\text { Treatment } \\
\text { completed (\%) }\end{array}$ & \\
\hline EPTB & $45(51.7)$ & $175(60.3)$ & $220(58.4)$ \\
\hline $\begin{array}{l}\text { PTB - sputum } \\
\text { negative }\end{array}$ & $27(31)$ & $60(20.7)$ & $87(23.1)$ \\
\hline $\begin{array}{l}\text { PTB - sputum } \\
\text { positive }\end{array}$ & $14(16.1)$ & $48(16.6)$ & $62(16.4)$ \\
\hline $\begin{array}{l}\text { Disseminated } \\
\text { TB }\end{array}$ & $1(1.1)$ & $7(2.4)$ & $8(2.1)$ \\
\hline Total & $87(100)$ & $290(100)$ & 377 (100) \\
\hline
\end{tabular}

important reason for failure to control TB, and for causing a resurgence in TB worldwide.

In our study, $58.4 \%$ patients had extrapulmonary TB while $39.5 \%$ had pulmonary TB. The mortality among the study population observed was $23.07 \%$ which was similar to the findings in a study of HIV-TB co-infected patients in Coastal South India by Kumar N et al where the mortality recorded was $18.8 \%$.

A study conducted in Shimla by SK Sharma, Alladi Mohan and Tamilarasu Kadhiravan also supported the observation that the prevalence of extra-pulmonary tuberculosis was more in co infected cases. ${ }^{8}$ But, there are reports with pulmonary involvement in higher proportions $(73 \%)$ as in a study conducted by Shastri et al. ${ }^{9}$

Globally, the TB associated mortality in co-infected patients is three times higher than mortality among TB sans HIV patients. There are a number of possible explanations that have been proposed for the increased mortality among co-infected patients. The location and the extent of TB are influenced by the degree of immunosuppression, often increasing the difficulty of diagnosis and hence delaying treatment initiation, often resulting in higher mortality. Immunological studies have also shown that host responses to M. tuberculosis enhance HIV replication thus accelerating the natural progression of HIV and further depressing cellular immunity. ${ }^{10}$ Our study also underscores this in that, there was a strongly significant association between adverse clinical outcomes and low CD4 counts. There are other factors like adherence to treatment, nutrition status of the individual and incidence of drug toxicities though not evaluated in our study which are also important causes contributing to the morbidity and mortality in these patients. ${ }^{7}$

\section{Table 9: Pattern of TB and its outcome}

\begin{tabular}{|c|c|c|c|c|}
\hline \multirow[t]{2}{*}{ Location } & \multicolumn{2}{|c|}{ TB treatment outcome } & \multirow{2}{*}{$\begin{array}{c}\text { Total } \\
(\mathrm{n}=377) \\
(\%)\end{array}$} & \multirow[t]{2}{*}{$\mathrm{P}$ value $(\%)$} \\
\hline & $\begin{array}{c}\text { Death } \\
(n=87) \\
(\%)\end{array}$ & $\begin{array}{l}\text { Treatment } \\
\text { completed } \\
(\mathrm{n}=290)(\%)\end{array}$ & & \\
\hline Pulmonary & $41(47.1)$ & 108 (37.2) & $149(39.5)$ & $0.098+$ \\
\hline Lymph node & $16(18.4)$ & $72(24.8)$ & $88(23.3)$ & 0.213 \\
\hline Abdominal TB & $15(17.2)$ & $52(17.9)$ & $67(17.8)$ & 0.883 \\
\hline Pleural effusion & $1(1.1)$ & $32(11)$ & $33(8.8)$ & $0.004^{\star *}$ \\
\hline TB Meningitis & $11(12.6)$ & $16(5.5)$ & $27(7.2)$ & $0.024^{*}$ \\
\hline Miliary TB & $1(1.1)$ & $7(2.4)$ & $8(2.1)$ & 0.473 \\
\hline Spinal TB & $2(2.3)$ & $1(0.3)$ & $3(0.8)$ & $0.072+$ \\
\hline Pharyngeal & $0(0)$ & $1(0.3)$ & $1(0.3)$ & 0.583 \\
\hline Genito-Urinary TB & $0(0)$ & $1(0.3)$ & $1(0.3)$ & 0.583 \\
\hline
\end{tabular}

Chi-Square test 


\begin{tabular}{|c|c|c|c|c|}
\hline \multirow[t]{2}{*}{ CD4 } & \multicolumn{2}{|c|}{ TB treatment outcome } & \multirow[t]{2}{*}{ Total } & \multirow[t]{2}{*}{$P$ value } \\
\hline & Death & Treatment completed & & \\
\hline Baseline & $107.71 \pm 114.21$ & $216.10 \pm 177.51$ & $191.76 \pm 171.37$ & $<0.001^{* *}$ \\
\hline 6 months & $220.00 \pm 178.06$ & $304.61 \pm 188.44$ & $298.00 \pm 188.69$ & $0.054+$ \\
\hline 12 months & $330.89 \pm 304.09$ & $364.67 \pm 189.90$ & $362.85 \pm 196.53$ & 0.617 \\
\hline
\end{tabular}

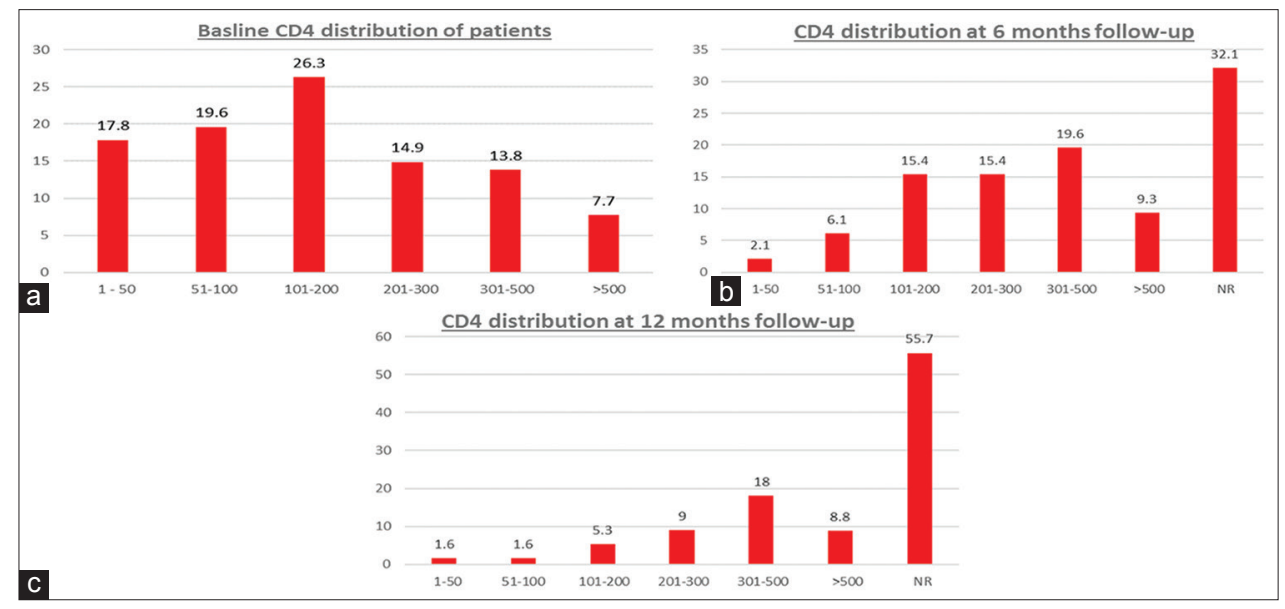

Figure 1(a), 1(b) and 1(c): represents the CD-4 counts of patients at different times of follow up. Among 377 patients in our study $23.1 \%$ ( $n=87$ ) succumbed to mortality during the time course while $76.9 \%$ completed the treatment successfully

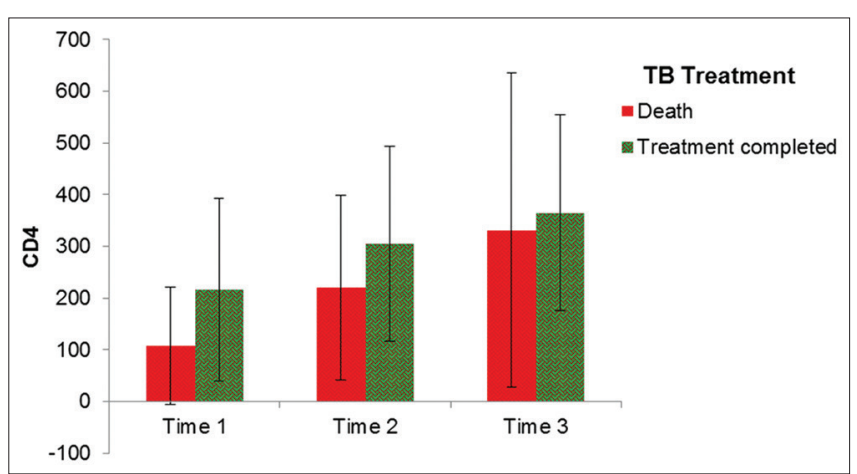

Figure 2: Association of CD-4 counts with adverse outcomes.

The strength of this study lies in the large size of the coinfected cohort, and thus the results are likely to represent the majority of those accessing HIV or TB care in the country.

\section{CONCLUSION}

In summary, the majority of co-infected patients had extrapulmonary TB. It was observed that there was a statistically significant increase in adverse outcomes in patients with pleural effusion and TB meningitis. Age, gender, the type of tuberculosis and the treatment category did not have a statistically significant association on the outcome.
We found that the TB associated mortality in co- infected patients did have a direct correlation with the stage of AIDS at presentation as there was a strongly significant association between low CD4 counts and adverse outcomes.

\section{REFERENCES}

1. Affandi JS, Kumar M, Agarwal U, Singh S and Price P. The search for a genetic factor associating with immune restoration disease in HIV patients co-infected with Mycobacterium tuberculosis. Disease markers 2013; 34(6):445-449.

2. Olowe OA, Makanjuola OB, Adekanmi AS, Adefioye OJ and Olowe RA. Epidemiological characteristics and clinical outcome of HIV-related tuberculosis in a population of TB patients in South-Western Nigeria. European Journal of Microbiology and Immunology 2017; 7(2):127-132.

3. Geldmacher C, Zumla A and Hoelscher M. Interaction between HIV and Mycobacterium tuberculosis: HIV-1-induced CD4 T-cell depletion and the development of active tuberculosis. Current opinion in HIV and AIDS 2012; 7(3):268-274.

4. World Health Organization. Global tuberculosis report 2016.

5. Tanwar S, Rewari BB, Rao CD and Seguy N. India's HIV programme: successes and challenges. Journal of virus eradication 2016; 2(Suppl 4):15.

6. Palchaudhuri $R$, Niggl $M$ and Palmer CS. Eliminating HIV \& AIDS in India: A roadmap to zero new HIV infections, zero discrimination \& zero AIDS-related deaths. The Indian journal of medical research 2016; 144(6):789.

7. Kumar N, Aithal S, Unnikrishnan B, Ramapuram J, Thapar R, Mithra P, et al. Predictors of mortality among a cohort of HIV/ AIDS patients on anti-retroviral therapy in coastal South India. HIV \& AIDS Review. International Journal of HIV-Related 
Problems 2017;16(1):18-23.

8. Sharma SK, Mohan A and Kadhiravan T. HIV-TB co-infection: epidemiology, diagnosis \& management. Indian J Med Res 2005;121(4):550-567.

9. Shastri S, Naik B, Shet A, Rewari B and De Costa A. TB treatment outcomes among TB-HIV co-infections in Karnataka, India: how do these compare with non-HIV tuberculosis outcomes in the province? BMC public health 2013; 13(1):838.

10. Tayler-Smith K, Zachariah R, Manzi M, Kizito W, Vandenbulcke A, Sitienei J, Chakaya J, et al. Antiretroviral treatment uptake and attrition among HIV-positive patients with tuberculosis in Kibera, Kenya. Tropical medicine \& international health 2011;16(11):1380-1383

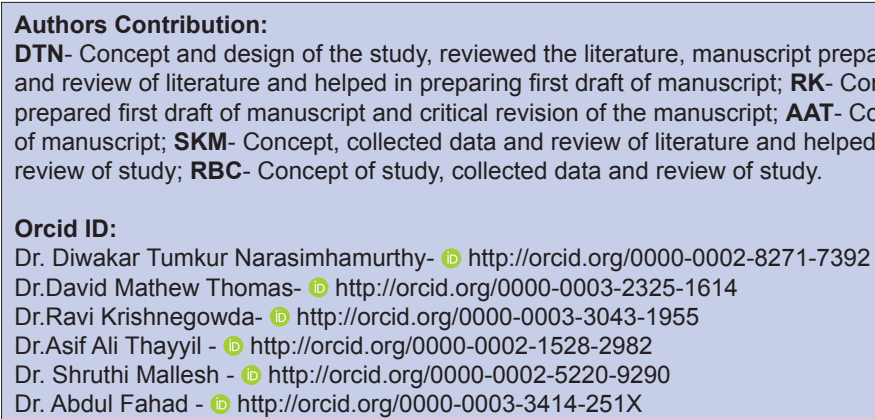

